\title{
Is anti-D immunoglobulin unnecessary in the domiciliary treatment of miscarriages?
}

\author{
CB Everett
}

General practitioners have been repeatedly told that they must give anti-D immunoglobulin to all $\mathrm{Rh}$ negative women who bleed in early pregnancy. This advice was issued by the Department of Health and Social Security in $1976^{1}$ and restated many times elsewhere. Last year Entwistle and his colleagues said that the present failure of general practitioners to follow this advice was a substantial source of new sensitisations preventing further reductions in the incidence of haemolytic disease of the newborn. ${ }^{2}$

Superficially it appears that general practitioners are being negligent. The results of a survey in Wessex showed that $77(74 \%)$ general practitioners did not give anti-D immunoglobulin to women with threatened abortions and $29(28 \%)$ did not give it to women with complete miscarriages whom they treated at home. ${ }^{3}$ Since these results were published I have made a determined but unsuccessful effort to find specific evidence about new sensitisations that occur in women with miscarriages who are not admitted to hospital. Many reports talk about "abortions" but fail to distinguish between abortions that are spontaneous and those that are surgically induced: they are two separate conditions. For example, in an analysis of deaths due to $\mathrm{Rh}$ haemolytic disease Clarke et al reported on the deaths due to previous "abortions," but the information provided to them did not give sufficient detail for subsequent analysis (personal communication) ${ }^{4}$

After commenting on general practitioners Entwistle et al said that sensitisation occurs as early as the ninth week of pregnancy. ${ }^{2}$ This comment was based on data from surgically induced abortions reported by Queenan, who claimed that sensitisation is facilitated by anaesthesia and curettage, neither of which is carried out in general practice.

In 1986 Tovey wrote that sensitisation was not a notable problem in early pregnancy. ${ }^{6}$ In 1987 Hussey reported on a small survey in Mersey, and she concluded that new sensitisations did not particularly occur after early spontaneous abortions. ${ }^{7}$ In 81 newly sensitised women the cause was identified in 58; in one woman only was this due to lack of anti-D after a spontaneous miscarriage. She did not state whether this omission occurred at home or in hospital.

Katz may be the only one who has looked at the conditions that we face in general practice. ${ }^{8}$ Comparing healthy pregnant women with those who had bleeding in early pregnancy, he found that there was no appreciable increase in sensitisations among women with a threatened or complete miscarriage up to the sixteenth week unless curettage was carried out. This little quoted article deserves reappraisal because if Katz's findings are correct it seems that anti-D immunoglobulin would not be required for the many women who are treated at home.

I have calculated that there are at least as many women who complete their miscarriages at home as go into hospital. If $15 \%$ of pregnancies end in a miscarriage then in England and Wales during 1983 of 625000 deliveries there would have been 110000 miscarriages.
There were 55000 hospital admissions that year, and $94 \%$ of those women received what is often a routine evacuation under a general anaesthetic. ${ }^{3}$ The other 55000 women remained at home. Only $217(17 \%)$ general practitioners in the Wessex survey said that they would always admit women with apparently complete miscarriages to hospital.

The problems that general practitioners experience in treating these women, who are solely in their care, are due to many causes, ${ }^{3}$ some of which were mentioned by Collinge. ${ }^{9}$ But general practitioners are not the only ones failing to give anti-D immunoglobulin in early pregnancy. From the results of a postal survey Contreras et al reported on ambivalent attitudes among some haematologists and obstetricians. ${ }^{10}$ Entwistle et al suggested that all women who cannot readily be grouped should be given anti-D immunoglobulin. ${ }^{2}$ This would mean that of every seven doses given six would be wasted on $\mathrm{Rh}$ positive women. Anti-D immunoglobulin is available in our area only from the hospital fridge on a named patient basis. It is still in short supply, and this was discussed in two letters to the $B M \mathcal{F}^{11}{ }_{12}$

Some of the confusion that now surrounds us might have been avoided if all reports had clearly stated the type of "abortion" that was causing new sensitisations. Abortion is an ugly word and heartily disliked by our patients. If we use it ambiguously it will never serve us well, and perhaps we should now abandon it.

In order to see the problem more clearly would it be possible in future for haematologists to report separately the number of women who become sensitised after (i) threatened miscarriages (early and late), (ii) spontaneous miscarriages (treated conservatively or with curettage), and (iii) the termination of unwanted pregnancies? Only when general practitioners are given this information will we fully understand when anti-D immunoglobulin is required, and it would encourage us to make the extra effort (where necessary) to identify and protect those $\mathrm{Rh}$ negative women who are greatly at risk.

1 Department of Health and Social Security. Haemolytic disease of the newborm. London: HMSO, 1976. (Addendum 1981)

2 Entwistle CC, Boswell PJ, Tovey LAD. Reported management of threatened miscarriage by general practitioners in Wessex. Br Med f 1987;295:998.

3 Everett $\mathrm{CB}$, Ashurst H, Chalmers I. Reported management of threatened miscarriage by general practitioners in Wessex. Br Med $\mathcal{F}$ 1987;295:583-6. 4 Clarke CA, Whitfield AGW, Mollison PL. Deaths from Rh haemolytic disease in England and Wales in 1984 and 1985. Br Med J 1987;294:1001.

5 Queenan JT. Role of Rh o (D) immune globulin in induced abortions. Clin Obstet Gynecol 1971;14:235-44.

6 Tovey LAD. Haemolytic disease of the newborn-the changing scene. $\mathrm{Br} f$ Obstet Gynaecol 1986;93:960-6.

7 Hussey RM. Why women are not receiving anti-Rh prophylaxis. $\mathrm{Br} \mathrm{Med} \mathcal{F}$ 1987;294:119.

$8 \mathrm{Katz} \mathrm{J}$. Transplacental passage of fetal red cells in abortion: increased incidence after curettage and effect of oxytocic drugs. Br Med $\mathcal{F} 1969$;iii: 84-6.

9 Collinge JD. Reported management of threatened miscarriage by GPs in Wessex. Br Med f 1987;295:1415.

10 Contreras $M$, de Silva $M$, Hewitt PE. Why women are not receiving anti-Rh prophylaxis. Br Med f 1986;293:1373.

11 Entwistle CC, Tovey LAD. Supplies of anti-Rh(D). BrMed f1988;296:132.

12 de Silva $M$, Teesdale P, Contreras M. Supplies of anti-Rh(D). Br Med $\mathcal{J}$ 1988;296:132.

(Accepted 13 fuly 1988) 
Dr Everett has raised an important question, to which, unfortunately, there is no satisfactory answer. As he implies evidence that $\mathrm{R} h$ immunisation can be initiated by spontaneous miscarriages occurring in the first three months is very slender. Is it then really necessary to ensure that after these events anti-D immunoglobulin is given?

Two kinds of evidence would support the idea that anti-D immunoglobulin should be given after spontaneous miscarriages. Firstly, if it was shown that fetal red cells are sometimes present in the maternal circulation, and, secondly, if it was shown that a spontaneous miscarriage can sometimes initiate $\mathrm{Rh}$ immunisation.

It is difficult to obtain decisive evidence about transplacental haemorrhage after early terminations of pregnancy. This is partly because of the increase in fetal haemoglobin concentration in maternal cells, which may occur as early as the eighth week of pregnancy and which makes it almost impossible to detect small numbers of fetal cells with certainty, and partly because the amounts of fetal blood in the maternal circulation must in any case be very small. In one study in which an attempt was made to estimate the extent of transplacental haemorrhage after induced termination of pregnancy haemorrhage was estimated to be greater than $0.05 \mathrm{ml}$ in $5 \%$ of cases and greater than $0.5 \mathrm{ml}$ in $2 \%$, whereas after spontaneous miscarriages it was always less than $0.05 \mathrm{ml} .{ }^{1}$ Even $0.03 \mathrm{ml}$ of red cells, however, may be enough to induce $R h$ immunisation.

Evidence that spontaneous miscarriages occurring in the first trimester can, in fact, initiate Rh immunisation scarcely exists. In one series of women who had not been given anti-D immunoglobulin after an abortion occurring during the first 12 weeks of pregnancy and who developed anti-Rh during the following pregnancy ${ }^{3}$ (supplemented by L A D Tovey, personal communication) there were eight in whom the miscarriage had been spontaneous. In these eight women anti-Rh developed only during the last weeks of the succeeding pregnancy and might have been initiated by the second pregnancy rather than by the miscarriage. Although there is little evidence that spontaneous miscarriage occurring in the first 12 weeks can initiate $\mathrm{Rh}$ immunisation, there is plenty of evidence that induced termination of pregnancy occurring as early as 12 weeks can do so. ${ }^{2}$

More information about the risk of $\mathrm{Rh}$ immunisation after spontaneous miscarriage may eventually become available from careful observations on women who for whatever reason have not been given anti-D immunoglobulin. Meanwhile, it might be a good rule to say that anti-D immunoglobulin should be given whenever the spontaneous miscarriage occurs later than 12 weeks. This rule is, of course, somewhat arbitrary but reflects the fact that the extent of transplacental haemorrhage increases as pregnancy advances. If the woman has no living child it is of course particularly important to take all possible steps to prevent $\mathrm{Rh}$ immunisation.

I do not agree with the suggestion of giving $\mathrm{Rh}$ immunoglobulin to all women after sensitising episodes if the $\mathrm{Rh}$ group is not known. It should be possible for the $\mathrm{ABO}$ and $\mathrm{Rh}$ groups of all pregnant women to be known at an early stage regardless of threatened or actual miscarriage. Such information would help to ensure that $\mathrm{Rh}$ negative women were given anti-D immunoglobulin after terminations of pregnancy, ectopic pregnancies, amniocenteses, versions, and so on.

Although the importance of giving anti-D immunoglobulin to previously unimmunised $\mathrm{Rh}$ negative women after any episode known to carry a substantial risk of inducing immunisation is accepted, it does not seem necessary to give anti-D immunoglobulin to women after spontaneous abortion in the first trimester of pregnancy.

1 Jørgensen J. Foeto-maternal blødning. Copenhagen, Denmark: University of Copenhagen, 1975. (MD thesis.)

2 Mollison PL, Engelfriet CP, Contreras M. Blood transfusion in clinical medicine Oxford: Blackwell Scientific Publications, 1987:650-1.

3 Tovey LAD. Haemolytic disease of the newborn-the changing scene. Br F Obstet Gynaecol 1986;93:960-6.

(Accepted 15 fuly 1988

\section{WORDS}

etymological loOKalikes. Here are a few examples of pharmaceutical terms whose spelling is similar, but whose origins differ.

THEOBROMINE and THEOPHYLLINE are two dimethyl xanthines with slightly differing actions. While theophylline is a powerful relaxant of smooth muscle (whence its use in the relief of asthmatic bronchospasm) and moderately active cerebral stimulant (occasionally causing insomnia), theobromine by contrast is a comparatively weak relaxant and has negligible stimulant effect, which is why a drink of hot chocolate makes a popular nightcap.

THEO- and THEOBROMINE. Although the "theo"-moiety occurs in the names of both these pharmacologically related substances, the roots are unrelated. The name Theobroma (Gk theos, god + Gk broma, food) was chosen by Linnaeus (1760) to denote the genus of which one species, $T$ cacao, yields seeds that are the source of cocoa and chocolate. In the seventeenth and eighteenth centuries chocolate was a very highly regarded beverage, and "food of the gods" would have been an appropriate epithet. THEOPHYLLINE (mod L thea, tea + combining "o" + Gk phyllon, leaf) was first obtained from tea leaves. The main alkaloid in tea, however, is caffeine, so named from its presence also in coffee. Of the methylxanthines, caffeine is the most potent as a cerebral stimulant. Xanthine, incidentally, is named after the yellow compound yielded with nitric acid (Gk xanthos, yellow).

BROM- We have seen that there is no bromine in theobromine. Yet the "-brom-" moiety in pharmacological terms almost always denotes the presence of that element (Gk bromos, stink) (19 March, page 835). The BROMIDES of sodium, potassium, and ammonium were the most widely used sedatives before being displaced by the barbiturates in the third decade of the twentieth century. Bromine is present in many a pharmaceutical molecule, most recently perhaps in the ergot derivative, BROMOCRIPTINE.

Other "brom-" lookalikes are the BROMES (Gk bromos, oats; yes, the Greeks also had their homonyms), a species of grass. Hubbard describes 12 common British varieties, ${ }^{1}$ only one of which, Upright Brome, is of value as fodder. All bromes may provoke hay fever (seasonal allergic rhinitis) when producing pollen - a condition which, by a kind of poetic justice, may be treated with the bromine containing antihistamine, BROMPHENIRAMINE.

Finally we come to the BROMALINS. Bromalins are a mixture of proteolytic enzymes derived from the pineapple plant Ananas comosus. Asthma and rhinitis have been reported following long exposure to bromalins in the pharmaceutical industry. ${ }^{2}$ There is no bromine in bromalins. Linnaeus named the pineapple genus Bromelia after a Swede called Olaus Bromel.

If you are thinking of retiring for the night with a cup of chocolate I should point out that, while theobromine has negligible stimulant effect, the beverage will contain about $20 \mathrm{mg}$ of caffeine.

1 Hubbard CE. Grasses: a guide to their structure, identification, uses, and distribution in the British Isles. Harmondsworth: Penguin, 1968:68-89.

2 Baur X, Fruhmann G. Allergic reactions including asthma to the pineapple protease bromelain following occupational exposure. Clinical Allergy 1979;9:443-50. 